\title{
ALÉM DAS PORTARIAS: DESAFIOS DA POLÍTICA DE SAÚDE MENTAL ${ }^{1}$
}

\author{
Cristina Amélia Luzio*
}

Silvio Yasui"

\begin{abstract}
RESUMO. O presente trabalho pretende analisar algumas portarias da Política Nacional de Saúde Mental implementadas no país no período de 1990/2006, pois elas se constituíram em importantes dispositivos para induzir mudanças do modelo assistencial na Saúde Mental. Aponta-se para os documentos mais relevantes e destacam-se suas consequências e problemas para a construção da atenção psicossocial. Ao final, conclui-se que o avanço da Reforma Psiquiátrica brasileira não pode ficar descolado de ações no interior do SUS. Dessa forma, os gestores de saúde, ao lado dos demais segmentos da sociedade, passaram a ser atores importantes na utilização dos recursos contidos na nova legislação de fato voltados para a construção de um novo modo de cuidado na saúde mental que possibilite o reposicionamento do sujeito no mundo, considerando-se sua dimensão subjetiva e sociocultural.
\end{abstract}

Palavras-chave: Política de saúde; reforma psiquiátrica; atenção psicossocial.

\section{BEYOND THE GOVERNMENTAL DECREES: THE CHALLENGES OF MENTAL HEALTH POLICY}

\begin{abstract}
The present work intends to analyze some of the Governmental decrees of the National Mental Health Policy implemented in the country in the 1990/2006 period, so they establish themselves in important devices to induce changes in Mental Health's care model. It indicates to the most relevant document and highlights its consequences and problems for the construction of psychosocial care. It was concluded at the end that the advancement of Brazilian Psychiatric Reformation is increasingly linked to the construction and consolidation of the Unified Health System (SUS). In this way, the health managers, along with the others segments of society, had started to be important actors in the use of the resources contained in the new legislation actually focused on the construction of a new way of care in the mental health that makes possible a new position of the citizen in the world, considering its subjective, social and cultural dimension.
\end{abstract}

Key words: Health policy; psychiatric reform; psychosocial care; mental health.

\section{MÁS ALLÁ DE LAS NORMAS: LOS DESAFÍOS DE LA POLÍTICA DE SALUD MENTAL}

RESUMEN. Este trabajo pretiende analizar algunas Normas de la Política Nacional de Salud Mental practicadas en el país en el período de 1990/2006, puesto que ellas se constituyeron en importantes dispositivos para inducir a cambios del modelo asistencial en la Salud Mental. Se señalan los documentos más relevantes y se destacan sus consecuencias y problemas para la construcción de la atención psicosocial. Al final se concluye que el avance de la Reforma Psiquiátrica brasileña se acerca cada vez más a la construcción y consolidación del Sistema Único de Salud (SUS). De tal manera, los encargados de la salud, al lado del los otros segmentos de la sociedad, habían comenzado a ser agentes importantes en el uso de los recursos contenidos en la nueva legislación se vuelven hacia la construcción de una nueva manera del cuidado en la salud mental y eso él hace posible el nuevo lugar del ciudadano en el mundo, considerándose su dimensión subjetiva y sociocultural.

Palabras-clave: Política de salud; reforma psiquiátrica; atención psicosocial; salud mental.

1 Texto elaborado a partir das teses de doutorado dos autores e uma versão revista e ampliada da exposição no III Congresso Internacional e IX Semana de Psicologia - coletividade e subjetividade na Sociedade Contemporânea nos dias 18 a 21 de setembro de 2007. Maringá-Pr, no período de 18 a 21 de setembro de 2007.

Psicóloga, Doutora em Saúde Coletiva. Professora da Faculdade de Ciências e Letras, da Universidade Estadual Paulista/Assis.

\# Psicólogo, Doutor em Saúde Pública. Professor da Faculdade de Ciências e Letras, da Universidade Estadual Paulista/Assis. 
Foi em um cenário desfavorável de ampliação global das políticas econômicas neoliberais que, paradoxalmente, a Reforma Sanitária foi se consolidando como uma política pública ao longo da década de 1990, com a criação de práticas inovadoras que fortaleceram a implantação do Sistema Único de Saúde (SUS). Paralelamente, alguns governos municipais procuraram construir uma nova rede de serviços e cuidados que oferecessem possibilidades de prestar a atenção psicossocial, implantando e implementando as propostas da Reforma Psiquiátrica, até então apenas um intenso movimento social constituído por trabalhadores da saúde mental. As experiências inovadoras e exitosas realizadas em algumas cidades inspiraram e influenciaram a configuração de um novo desenho da política, por intermédio de vários mecanismos e instrumentos institucionais.

O Ministério da Saúde, a partir de 1990, editou várias Portarias, tanto para modificar a sistemática de remuneração das internações psiquiátricas, visando a reduzir o tempo de internação, como para criar outros procedimentos relativos à saúde mental, além das internações e consultas ambulatoriais, dando início à atual Política Nacional de Saúde Mental.

$\mathrm{O}$ presente artigo pretende apresentar em qual contexto de implantação do SUS as portarias da Política Nacional de Saúde Mental foram publicadas e analisar as principais portarias implementadas no país entre 1990/2006, pois se constituíram em dispositivos para introduzir mudanças do modelo assistencial em Saúde Mental.

\section{A DÉCADA DE 1990: A BUSCA DA MUDANÇA DO MODELO ASSISTENCIAL}

No Brasil, a década de 1990 começou com a posse do governo do presidente Fernando Collor de Mello, que logo apresentou os aspectos que marcariam a sua administração: início da implementação da política neoliberal, retardando o avanço da Reforma Sanitária, que havia obtido importantes conquistas nos anos anteriores.

Como exemplo dessas conquistas podemos citar a aprovação da Lei Orgânica da Saúde (Lei 8080), aprovada graças a uma intensa mobilização e articulação das forças políticas em favor da Reforma Sanitária. Contudo, todos os artigos referentes à participação social foram vetados, obrigando a uma nova mobilização e à aprovação de uma nova lei, a Lei 8142, que dispõe sobre a realização das Conferências de Saúde e sobre os Conselhos de Saúde, tornando-os obrigatórios. A IX Conferência Nacional de Saúde foi organizada e realizada após intensas pressões e já sob o quadro de crise institucional que conduziria o presidente Collor ao seu impeachment, no ano de 1992. O lema não oficial daquela conferência, retirado de um documento preparatório, foi: A Ousadia de Fazer Cumprir a Lei.

Mesmo após o impeachment de Collor, a política econômica continuou a seguir o modelo de reforma neoliberal imposto pelos organismos internacionais. É nesse quadro economicamente desfavorável e de retrocesso em relação aos avanços conquistados na década de 80 que a Reforma Sanitária foi implementando um de seus mais relevantes eixos do SUS: a descentralização.

Levcovitz, Lima e Machado (2001) afirmam que, apesar das diferenças nas análises, há um consenso sobre os avanços no âmbito da descentralização em saúde predominante no Brasil, caracterizando-a como sendo do tipo político-administrativo, envolvendo a transferência da esfera federal para a esfera estadual e a municipal não apenas de serviços, mas também de responsabilidades, poder e recursos. Ressaltam, porém, que a descentralização "não garante o caráter democrático do processo decisório e necessita ainda do fortalecimento das capacidades administrativas e institucionais do governo central na condução do processo" (Levcovitz, Lima \& Machado, 2001, p. 272).

Destarte, consolidação do SUS requer a existência de mecanismos de regulação que dêem conta do dinamismo desse processo. Nesse sentido, as Normas Operacionais Básicas, que tratam dos aspectos de divisão de responsabilidades, relações entre gestores e critérios de transferência de recursos federais para estados e municípios, passaram a representar instrumentos fundamentais para a concretização da descentralização estabelecida pela Constituição e constante na legislação do SUS.

Tal processo colocou em cena milhares de gestores municipais de saúde que passaram a se constituir, por vontade própria, ou compulsoriamente, por força da função que exerciam, em atores fundamentais no campo da saúde. O Conselho Nacional de Secretários Municipais de Saúde (CONASEMS), o Conselho Nacional de Secretários Estaduais de Saúde (CONASS) e os Conselhos Estaduais de Secretarias Municipais de Saúde (COSEMS), passaram a desempenhar um importante papel, especialmente a partir de 1994, ano em que foram constituídas as Comissões Intergestores Bipartites, reunindo municípios e governos estaduais, e a Comissão Intergestores Tripartite, reunindo municípios, governos estaduais e o governo federal. 
No âmbito dos municípios, a descentralização fortaleceu a constituição dos Conselhos Municipais de Saúde, órgãos colegiados, de composição paritária entre representantes do governo e da sociedade, com a função de controlar e deliberar sobre as questões referentes à implantação e implementação das ações de saúde do SUS. São mecanismos de participação e controle popular, buscando democratizar as relações entre o Estado e a sociedade.

A descentralização colocou o Ministério da Saúde e as secretarias municipais e estaduais de saúde como os principais atores indutores do processo da Reforma Sanitária, deslocando os movimentos sociais para um papel secundário. A definição do arcabouço jurídicolegal e da engenharia institucional, associada à questão sempre problemática do financiamento, transformou esse complexo processo em uma questão administrativo-gerencial. A lógica do financiamento e da administração ocupou um lugar de destaque, na agenda das mudanças.

Nesse contexto, a Reforma Psiquiátrica se construiu mediante a articulação dos novos serviços com outros segmentos dos movimentos sociais, tais como as associações de usuários e familiares, ONGs, sindicatos, etc. Essa estratégia estabeleceu uma diferença, principalmente nos anos noventa, entre a Reforma Psiquiátrica e a Reforma Sanitária: por um lado, ocupou espaços no aparelho estatal e por outro manteve uma identidade de movimento social, por meio do Movimento da Luta Antimanicomial e das associações de usuários. Nutrindo-se das cotidianas questões que surgiam no embate da construção da transformação da assistência, a Reforma Psiquiátrica se atualizava, também, com as questões sociais de seu tempo histórico.

A ocupação dos espaços no interior do aparelho estatal guiou-se pelas mesmas trilhas da Reforma Sanitária, com os mesmos riscos e problemas. No contexto da descentralização e da municipalização, a transferência de recursos financeiros da saúde mental se destinava apenas à internação e às consultas ambulatoriais. Serviços altamente complexos e modelos de propostas assistenciais, como o Centro de Atenção Psicossocial (CAPS) e os Núcleos de Atenção Psicossocial (NAPS), não existiam para o SUS.

Em janeiro de 1992 foi publicada a Portaria n. ${ }^{\circ}$ 224/92, a qual reafirmava os princípios do SUS, estabelecia diretrizes, regulamentava o funcionamento de serviços de saúde mental existentes à época e fixava normas para: equipes de saúde mental em unidades básicas de saúde e centros de saúde; ambulatórios de saúde mental; Núcleos de Atenção
Psicossocial (NAPSs) e Centros de Atenção Psicossocial (CAPSs); hospital-dia de psiquiatria; serviço de urgência psiquiátrica em hospital geral; leito ou unidade psiquiátrica em hospital geral; e hospital especializado em psiquiatria (Brasil, 2004).

Essa portaria cumpriu o importante papel de ser o documento de orientação e referência, nos sistemas locais de saúde, de implantação dos novos serviços substitutivos. Embora contivesse limitações, a Portaria 224/92, junto com outras portarias publicadas nos anos subsequentes, que estabeleciam diferentes remunerações das autorizações de internação hospitalar do SUS (AIH-SUS), de acordo com uma classificação em termos de adequação às exigências mínimas de funcionamento, foi um instrumento de fiscalização dos hospitais psiquiátricos, levando ao descredenciamento de centenas de leitos e de hospitais pelo País.

O desenho institucional proposto por essa Portaria era de uma organização da assistência em saúde mental segundo a lógica da hierarquização por níveis de assistência. Na descrição do NAPS/CAPS, que surge como um procedimento do SIA/SUS, a Portaria colocava aqueles serviços como "unidades de saúde locais/regionalizadas, que contam com uma população adstrita definida pelo nível local e que oferecem atendimento de cuidados intermediários entre o regime ambulatorial e a internação hospitalar(...)" (Brasil, 2004, p. 244). Assim, os NAPSs/CAPSs deveriam compor uma rede assistencial constituída de diversas unidades que tinham entre si uma relação hierárquica, incluído o hospital psiquiátrico. Não há, na Portaria, nenhuma menção a serviços substitutivos ou a uma mudança de modelo assistencial; e - o que é mais relevante, do ponto de vista da remuneração - não se caracterizava como um serviço, uma unidade, e sim como um procedimento. Dessa forma, vários ambulatórios de saúde mental se credenciaram com o "procedimento NAPS/CAPS", mas continuaram atendendo como um ambulatório. Houve uma ampliação do "menu" de ofertas de tratamento.

Amarante e Torre (2001) destacam que essa Portaria iguala experiências distintas, os CAPSs e os NAPSs, cujas inspirações teórico-conceituais e técnico-assistenciais foram diferentes, tornando-as apenas uma modalidade de serviço, aparentemente advinda de modelos idênticos, perdendo-se a pluralidade contida naqueles dois sistemas.

Entre as diferenças que caracterizam as instituições CAPS e NAPS podem-se salientar alguns aspectos. O CAPS foi implantado como um serviço intermediário entre o ambulatório e a internação psiquiátrica, funcionando em cinco dias da semana, 
por no máximo oito horas diárias, cuja proposta terapêutica era a de uma prática clínica centrada na vida cotidiana da instituição, de modo a permitir o estabelecimento de uma rede de sociabilidade para fazer emergir a instância terapêutica. Buscava inspiração essencialmente na análise institucional, na psiquiatria de setor.

O NAPS foi criado como um serviço substitutivo ao hospital psiquiátrico, portanto para funcionar durante as vinte e quatro horas. Ficava responsável pelo atendimento integral à demanda de Saúde Mental de uma região, principalmente aos casos graves, através de uma multiplicidade de ações, as quais tinham como objetivo a restituição do poder contratual do usuário, de modo a possibilitar a ampliação de sua autonomia. Os NAPSs foram inspirados essencialmente na experiência da psiquiatria democrática italiana.

Neste sentido podem-se observar, em ambas as experiências, diferenças importantes quanto ao lugar da abordagem clínica nos serviços assistenciais. As práticas criadas no NAPS decorriam de críticas severas à clínica psiquiátrica e psicológica como o encontro de identidades predefinidas, nas quais o médico e psicólogo são os detentores do saber e o paciente um mero objeto e, portanto, responsáveis pela reprodução de poderes, de ideologias e de doenças. As práticas desenvolvidas no CAPS sustentavam-se também na crítica dessa visão de clínica e procuravam a construção de uma clínica ampliada como encontro, capaz de produzir sentidos (Costa-Rosa, Luzio \& Yasui, 2003).

Cumpre, não obstante, repetir que, mesmo assim, foi um passo fundamental. Por ser um documento do Ministério da Saúde, a Portaria 224/92 deu legitimidade e legalidade a importantes experiências que estavam ocorrendo e possibilitou que estas fossem financiadas pelo SUS.

Ainda em 1992, foi realizada a II Conferência Nacional de Saúde Mental (II CNSM). Precedido de etapas municipais, regionais e estaduais, o evento contou com o envolvimento direto de cerca de vinte mil pessoas. As deliberações contidas em seu relatório estão em sintonia com as transformações ocorridas até aquele momento na assistência em Saúde Mental (Conselho Regional de Psicologia- $6^{\mathrm{a}}$ Região/SP, 1997).

Muitas propostas elaboradas na II CNSM se concretizaram na edição de portarias ministeriais e na criação da Comissão Nacional da Reforma Psiquiátrica, fatos que representaram a conquista de estratégicos espaços institucionais, transformando a Reforma Psiquiátrica em uma política pública oficial.
Por outro lado, foram realizados vários encontros nacionais do Movimento da Luta Antimanicomial, os quais $\mathrm{o}$ fortaleceram enquanto movimento social, firmando-o como um dos condutores do processo de transformação da Reforma Psiquiátrica nos campos assistencial, cultural e conceitual e mantendo um distanciamento crítico em relação à Política Nacional de Saúde Mental. O Movimento da Luta Antimanicomial (MLA) tem defendido uma posição de independência em relação ao aparelho estatal, ainda que muitos de seus atores tenham sido gestores das políticas municipais de saúde. É nessa condição que o MLA define sua participação, como representante do segmento da sociedade civil, nas comissões de reforma psiquiátrica criadas pelos Conselhos de Saúde nos vários níveis de governo.

Nesse período ocorreram também diversos encontros nacionais de Usuários e Familiares de Serviços de Saúde Mental. De maneira geral, tais encontros fazem contundentes críticas às práticas terapêuticas segregadoras e invasivas - como, por exemplo, o eletrochoque -, bem como a defesa dos direitos dos usuários.

Yasui (1999) destaca que tais encontros consolidaram a entrada desses atores no cenário da Reforma Psiquiátrica e reafirmaram seus princípios, uma vez que modificavam a posição de objeto dos usuários, construída historicamente pelas políticas públicas e pelas práticas psiquiátricas.

Em síntese, a partir de inúmeras experiências municipais inovadoras, associadas às reflexões e às propostas operadas pelo Movimento Reforma Psiquiátrica, foi possível propiciar sua maior visibilidade e sua disseminação entre os gestores, profissionais, usuários e a sociedade civil. Além disso, houve avanços no processo de transformação da atenção em Saúde Mental nos campos assistencial, jurídico e cultural, com base na construção de um projeto de atenção em Saúde Mental com características radicais e na criação de normas de fiscalização, vistoria e qualificação dos hospitais psiquiátricos. A Reforma Psiquiátrica igualmente se consolidava como um movimento reivindicatório de transformações que ultrapassavam as especificidades da área.

Tal situação provocou reações contrárias nos setores dominantes, principalmente entre os donos dos hospitais psiquiátricos. Esses grupos ampliaram os campos de sua ação, até então voltadas para atividades de lobistas nos corredores do poder. Procuraram construir estratégias de ocupação dos espaços coletivo-públicos. Uma das estratégias adotadas por esse segmento foi a ampliação da participação de seus 
representantes nas instâncias responsáveis pela definição dos princípios e diretrizes para Saúde Mental, especialmente nas conferências de Saúde Mental em suas diferentes etapas e nos Conselhos de Saúde, em seus diversos níveis.

Por outro lado, o grupo das indústrias farmacêuticas também tem procurado adaptar-se a esse novo cenário político-assistencial. Não tem medido esforços para mostrar sua adesão ao lema "Por uma Sociedade sem Manicômio". Alguns laboratórios farmacêuticos realizam concursos com produção dos usuários de serviços de Saúde Mental e propõem verbas para o patrocínio de eventos identificados com a luta antimanicomial.

Essas reações contrárias ou de aparente adesão encontram muitas vezes aliados em outros campos, como, por exemplo, a resistência dos segmentos contrários ao SUS, a resistência dos trabalhadores a aderir e realizar as transformações no interior das instituições de Saúde Mental e a resistência cultural a romper com a lógica manicomial.

De maneira geral, pode-se afirmar, a partir dos acontecimentos até aqui destacados, que o confronto de posições, embora possa reativar a inércia do instituído, possibilitou a emergências de novos atores e novos caminhos e a construção de ações transformadoras.

\section{A ENTRADA NO SÉCULO XXI: CONCRETIZANDO A ATENÇÃO PSICOSSOCIAL}

Nos primeiros anos do século XXI a Política Nacional de Saúde Mental manteve seu processo de consolidação por intermédio do Ministério da Saúde, que continuou criando novas portarias e resoluções, ampliando e aumentando a complexidade da rede de serviços. Assim foi publicada, em fevereiro de 2000, a Portaria n. ${ }^{\circ} 106 / 2000$, propondo a criação, no âmbito do SUS, de serviços residenciais terapêuticos. Como uma estratégia de inserção social, as residências terapêuticas devem constituir

\footnotetext{
uma modalidade assistencial substitutiva da internação psiquiátrica prolongada, de maneira que, a cada transferência de paciente do Hospital Especializado para o Serviço de Residência Terapêutica, deve-se reduzir ou descredenciar do SUS, igual $n^{\circ}$. de leitos naquele hospital, realocando o recurso da AIH correspondente para os tetos orçamentários do estado ou município que se responsabilizará pela assistência ao paciente e pela rede substitutiva de cuidados em Saúde Mental (Brasil, 2000, p. 49).
}

Essa portaria exige igualmente um projeto terapêutico centrado nas necessidades do usuário da Saúde Mental, com o objetivo de desenvolver sua autonomia em sua vida cotidiana e sua consequente reinserção social, bem como garantir os direitos dos usuários em geral, estabelecendo, ainda, normas e critérios para a inclusão desses serviços no SUS.

Embora represente um importante instrumento para os municípios poderem consolidar e ampliar suas redes de atenção psicossocial, essa portaria recebeu muitas críticas.

Os representantes dos empresários da assistência psiquiátrica, temendo o deslocamento dos recursos financeiros das internações para as residências terapêuticas e a consequente perda da sua fonte de ganhos fáceis, apontavam, entre outros problemas, para o risco da desassistência dos usuários internados. Os representantes do Poder Judiciário, juízes e promotores, questionavam a legalidade de passar aos usuários $\mathrm{o}$ dinheiro destinado anteriormente à internação. Influenciados ainda pela cultura da exclusão da doença mental e da periculosidade da pessoa considerada doente mental, receavam que esse novo serviço ferisse os direitos tanto dos usuários como da sociedade. Essa mesma cultura manicomial permeia as reações da população, pois muitos municípios que implantaram as residências terapêuticas têm encontrado resistências dos moradores vizinhos. Finalmente, muitos gestores e até mesmos trabalhadores responsáveis diretos pela implantação dos novos serviços, não assumem a criação das residências terapêuticas, nem mesmo reconhecem nelas um recurso terapêutico importante para a atenção em Saúde Mental (Luzio, 2003).

Em 2001, durante as comemorações do Dia Mundial da Saúde, cujo tema foi Saúde Mental: Cuidar, sim. Excluir, não, o Congresso Nacional aprovou, depois de mais de dez anos de intensa discussão, a Lei n. ${ }^{\circ} 10.216$, que dispõe sobre a proteção e os direitos das pessoas portadoras de transtornos mentais, redirecionando o modelo assistencial em Saúde Mental.

Embora saudada como a lei da Reforma Psiquiátrica, seu texto final está muito distante do saudável radicalismo do projeto original, de autoria do deputado Paulo Delgado, aprovado em 1989, o qual propunha claramente a "extinção progressiva do manicômio e sua substituição por outros serviços". Neste, tínhamos uma proposta de substituição de modelo e, na lei sancionada em 2001, a substituição transforma-se em proteção de direitos e redirecionamento. A mudança não foi apenas semântica, mas de essência. Transformada em um 
texto tímido, a lei aprovada mantém a estrutura hospitalar existente, regulando as internações psiquiátricas, e apenas acena para uma proposta de mudança do modelo assistencial.

Também, naquele mesmo ano, foi publicada a Portaria 469/GM, em 6 de abril, alterando a sistemática de remuneração dos procedimentos de internação em hospital psiquiátrico. Além disso, entre outras providências, propunha um processo de avaliação denominado Programa Nacional de Avaliação do Sistema Hospitalar (PNASH, 2002). Embora essa portaria tivesse como uma de suas justificativas a necessidade de qualificação técnica dos serviços de internação psiquiátrica, assim como a melhora de seus indicadores de qualidade, pela valorização dos hospitais menores, observa-se que ela permitiu a manutenção dos macro-hospitais psiquiátricos, apontando apenas que estes deveriam, futuramente, integrar-se a um programa de humanização e reestruturação (Brasil, 2001).

Ainda em 2001 aconteceu a III Conferência Nacional de Saúde Mental, em Brasília. O relatório final é extenso e a leitura de seus itens já demonstra a complexidade em que se transformou o campo da Reforma Psiquiátrica. Os aspectos mais importantes e as questões mais polêmicas estão contemplados em suas páginas, tais como: a reorientação do modelo assistencial em Saúde Mental pautada em uma concepção de saúde compreendida como processo, na perspectiva de produção de qualidade de vida, enfatizando ações integrais e promocionais de saúde; política de recursos humanos, salientando a relevância da formação e a valorização e importância do trabalhador de saúde mental na produção dos atos de cuidar; acessibilidade, reafirmando a meta de garantia de equidade de acesso a todos os serviços de saúde do SUS aos portadores de transtorno mental, incorporando-a nas agendas de saúde e na programação das ações de saúde; direitos e cidadania, ressaltando a prioridade para a formulação de políticas que fomentem a autonomia dos portadores de transtornos mentais, incentivando, desse modo, o exercício de cidadania plena, no lugar de iniciativas tutelares, além de propostas sobre financiamento e controle social (Brasil, 2002).

Em 2002, como consequência da III CNSM, uma nova portaria foi publicada, a 336/02, com importantes diferenças em relação à anterior: abandonou o termo NAPS, propondo um novo modelo de assistência, definindo o CAPS como "serviço ambulatorial de atenção diária que funcione segundo a lógica do território"; criou três diferentes tipos: "CAPS I, CAPS II e CAPS III, definidos por ordem crescente de porte/complexidade e abrangência populacional"; o CAPS passou a ser o articulador central das ações de saúde mental do município ou do modulo assistencial, de acordo com a Norma Operacional de Assistência à Saúde (NOAS).

A forma de financiamento foi alterada, passando este a ser realizado mediante o processo de Autorização de Procedimentos de Alto Custo (APAC). Dessa forma, os recursos disponíveis para o pagamento dos procedimentos do CAPS não estão contidos nos tetos financeiros dos estados e municípios e funcionam como recursos "extrateto". Se, por um lado, esse modelo de financiamento representou um avanço, já que colocou a proposta de mudança de modelo assistencial, implícita no CAPS, como uma política de relevância e uma ação estratégica do Ministério da Saúde, por outro lado trouxe problemas, porque mantém a mesma lógica de produtividade, ao remunerar atos vinculados a um determinado diagnóstico psiquiátrico de um indivíduo, ignorando toda uma série de ações realizadas no âmbito do território, previstas na Portaria 336/02, tais como a supervisão de unidades hospitalares, o apoio matricial a equipes da Atenção Básica, a articulação com outros setores e segmentos sociais, etc. Continuase a financiar a doença e não a promoção da saúde.

Se, ao longo dos anos 1990, a Reforma Psiquiátrica manteve uma estreita relação com os movimentos sociais, no raiar deste novo milênio começa a padecer do mesmo mal que acometeu a Reforma Sanitária. O processo de institucionalização da Reforma Sanitária, por um lado, foi um passo importante e decisivo para a consolidação de um projeto de saúde que se contrapõe ao modelo hegemônico, mas, por outro lado, esse processo encaminhou a Reforma Sanitária para longe dos movimentos e das organizações sociais, deslocando seu principal foco de luta da sociedade civil para o interior do aparelho estatal. Stotz (1994) afirma que o Estado passa a ser visto como um sujeito diante do qual se situam outros sujeitos, estes despojados de suas encarnações sociais e de poder para produzir a política pública. Tem-se a impressão de que os principais atores estão nos gabinetes ministeriais, produzindo normas e portarias, e não mais nas forças vivas da sociedade, nas instituições e nos serviços, como ativos protagonistas políticos.

Essa ênfase nos processos de regulação como indutores da política do SUS transforma a potencialidade criativa e transformadora daqueles atores em uma servidão às normas e portarias. Não há mais oposição, tensão, questionamento - pelo contrário, as críticas, geralmente oriundas dos setores 
acadêmicos, passam a ser vistas como ataque ou obstáculo a um processo que, ao se institucionalizar, perdeu a sua dimensão histórica, parecendo obedecer apenas a uma lógica de administração dos recursos financeiros disponíveis e afetando de maneira danosa o modelo assistencial. Sérgio Arouca sublinha a urgente necessidade de se retomarem os princípios básicos do SUS, entre eles o conceito de saúde/doença ligado ao trabalho, ao saneamento, ao lazer e à cultura, o que implica discutir "a saúde não como política do Ministério da Saúde, mas como uma função de Estado permanente". Arouca destaca o dano das políticas econômicas ao SUS da seguinte forma:

O modelo assistencial é anti-SUS. Aliás, o SUS como modelo assistencial está falido, não resolve nenhum problema da população. Essa lógica transformou o governo num grande comprador e todas as outras instituições em produtores. A Saúde virou um mercado, com produtores, compradores e planilhas de custos. O modelo assistencialista acabou universalizando a privatização (Arouca, 2002, p.19).

Campos (1997) já alertava, no início dos anos 90, para a necessidade de se repensar a Reforma Sanitária, recolocando a importância do cotidiano dos serviços, com seus processos de trabalho e de gestão, com seus atores com necessidades, potencialidades e demandas, enfim, com sua micropolítica como estratégia de transformação.

A Reforma Psiquiátrica se ressentiu desse mesmo problema. A sua institucionalização transformou o Ministério da Saúde em seu principal ator e indutorchefe dos ritmos e dos rumos do processo. Parece não haver mais espaço para experiências que não sigam os parâmetros estabelecidos nas portarias, que, ironicamente, têm como inspiração as experiências do CAPS e dos NAPSs, as quais trazem a marca da invenção e da criação que se construíram e obtiveram seu reconhecimento antes dessas regulações.

Se a Portaria 224/92 incentivou a criação de diversas unidades assistenciais espalhadas pelo país muitas com o nome de NAPS ou de CAPS - que acabaram por se transformar em sinônimos de unidades assistenciais de vanguarda, a Portaria 336/02, em função da mudança no financiamento, está contribuindo para a ampliação do número de CAPSs em um ritmo muito mais veloz. No período de 1992 a 2001 o número de serviços credenciados como NAPS/CAPS subiu de 22 para 295, enquanto o número de CAPSs credenciados até o ano de 2.006 atingiu a marca de 1.011 (Brasil, 2007). Do ponto de vista dos gestores municipais, a Portaria 336/2002 vem despertando grande interesse, muito mais como fonte de captação, para a saúde, de recursos fora do teto do que pela mudança do modelo assistencial.

Essa velocidade pode induzir a um perigoso e crucial equívoco: o CAPS ser considerado e implantado como mais um serviço de saúde mental, isto é, uma unidade isolada, em que se executam em nível ambulatorial ações próprias de profissionais. $\mathrm{O}$ CAPS é um dispositivo no contexto da mudança do modelo assistencial em Saúde Mental, e como tal, deve articular as instâncias de cuidados em Saúde Mental desenvolvidas na Atenção Básica em saúde, no Programa de Saúde da Família, na rede de ambulatórios e nos hospitais, bem como as atividades de suporte social, como trabalho protegido, lazer, residências terapêuticas e atendimento das questões previdenciárias e de outros direitos. Neste sentido, é mais do que um serviço: é uma estratégia de mudança do modelo de assistência que inclui necessariamente a reorganização da rede assistencial a partir de uma lógica territorial, o que significa ativar os recursos existentes na comunidade para compor e tecer as múltiplas estratégias de cuidado implícitas nessa proposta. Além disso, mais do que reorganização, tal estratégia se relaciona intimamente com uma proposta política de organização e de assistência à saúde (Brasil, 2002).

Outra consequência do relatório da III CNSM foi o início do processo de avaliação dos hospitais psiquiátricos, através do Programa Nacional de Avaliação do Sistema Hospitalar (PNASH). O MS editou a Portaria n. ${ }^{\circ}$ 251/GM, de 31 de janeiro de 2002, e a Portaria n..$^{\circ} 77$, de 01 de fevereiro de 2002, começando o processo de avaliação e reclassificação dos hospitais psiquiátricos, o qual teve como objetivo melhorar a qualidade do tratamento aos usuários internados, de modo a viabilizar maior remuneração para os hospitais que prestavam melhores serviços (Brasil, 2004).

Os hospitais psiquiátricos integrantes do SUS foram avaliados por intermédio do PNASH/psiquiatria, no primeiro semestre de 2002, sob a responsabilidade dos Grupos Técnicos de Organização e Acompanhamento das Ações Assistenciais das Secretarias Estaduais, com a participação de outros profissionais convocados por decisão do gestor local. A metodologia do processo contemplou a avaliação do gestor e dos usuários. A avaliação do gestor consistia na análise de informações e documentos e vistoria criteriosa realizada pela equipe técnica, acompanhada pela direção dos hospitais. A avaliação dos usuários foi 
feita pela equipe técnica, por meio de entrevistas com os pacientes de longa permanência e com alta hospitalar recente (Brasil, 2002).

Por fim, no período de 2002 a 2006, diversas outras portarias foram publicadas, e, consolidando o programa das residências terapêuticas, foi promulgada a Lei 10.708/2003, que instituiu o auxílio-reabilitação psicossocial para pessoas acometidas de transtornos mentais egressos de internações. Também destacamos: a Portaria 52/2004, que dispõe sobre o Programa Anual de Reestruturação da Assistência Hospitalar Psiquiátrica, no SUS, e reafirma a política de redução de leitos (Brasil, 2004); a Portaria GM 245/2005, que cria um incentivo financeiro para os municípios que estão implantando o CAPS (Brasil, 2005a); a Portaria Interministerial 353/2005, que nomeia o Grupo de Trabalho de Saúde Mental e Economia Solidária (Brasil, 2005b); a Portaria 1174/2005, que institui o Programa de Qualificação dos CAPSs, possibilitando que a equipe pudesse contar com supervisão clínicoinstitucional (Brasil, 2005c); a Portaria 678/2006, que institui a Avaliação, Monitoramento, Supervisão e Apoio Técnico aos Centros de Atenção Psicossocial e outros serviços da rede pública de saúde mental do SUS (Brasil, 2006a); e por fim, a Portaria Interministerial 3347/2006, que cria o Núcleo Brasileiro de Direitos Humanos e Saúde Mental (Brasil, 2006b).

Essas recentes portarias demonstram que a construção da política pública de saúde mental, por um lado, está se ampliando, com uma preocupação com a qualificação das equipes e com a redução dos leitos psiquiátricos, e por outro, vai se tornando cada vez mais complexa, apontando para ações que transcendem o âmbito da saúde.

\section{CONSIDERAÇÕES FINAIS}

O avanço do processo de municipalização, principalmente com a implantação da NOB/96, quando houve o deslocamento da condução e gerenciamento das ações de assistência para os estados e municípios, teve como consequência uma vinculação do avanço da Reforma Psiquiátrica à criação e consolidação do SUS. A superação do modelo psiquiátrico tradicional e a construção de um novo modo de atenção em Saúde Mental não podem ficar descoladas de ações no interior do SUS.

Dessa forma, as secretarias municipais de saúde, o Conselho Estadual de Secretários Municipais de Saúde (COSEMS), o Conselho Nacional de Secretários Municipais de Saúde (CONASEMS), entre outros, passaram a ser atores importantes para fazer avançar a Reforma Psiquiátrica no SUS. O redirecionamento dos recursos, sendo de competência dos estados e municípios, deslocou o espaço político de negociação para os fóruns do SUS, como, por exemplo, o Conselho Municipal de Saúde, o Conselho Estadual de Saúde, comissões bipartites e tripartites.

Neste sentido Capistrano Filho (2000) enfatiza: "Temos que entender que lutamos para isso e vamos ter que travar essa batalha cultural, social e política pelo avanço da Reforma Psiquiátrica de município a município. (...) porque é lá, sobretudo (...) municípios que têm a chamada gestão plena, que vamos poder avançar, independente das variações das políticas federal ou estaduais, o processo da Reforma Psiquiátrica (...)" (Capistrano Filho, 2000, p. 24-5).

Por outro lado, o avanço não pode restringir-se ao âmbito das ações e dos mecanismos administrativos ou regulatórios, pois é urgente a necessidade de transformação do modelo assistencial. O novo modo de cuidado na saúde mental deve orientar-se pela superação do paradigma doença/cura e colocar entre parênteses a doença mental (o diagnóstico e todo o aparato de tratamento do modelo psiquiátrico), entrando em contato com o sujeito para conhecê-lo em sua experiência-sofrimento, com a finalidade de possibilitar seu reposicionamento no mundo, considerando-se sua dimensão subjetiva e sociocultural (Rotelli, 2001).

Nessa perspectiva, outro aspecto a ser observado em relação ao avanço da Reforma Psiquiátrica é que os novos serviços devem se constituir em rede, com espaços que favoreçam um distanciamento adequado das condições de vida dos usuários em situação de necessidade de proteção ou continência. Tornam-se necessárias múltiplas ações terapêuticas e uma rotina institucional ágil e plástica, capaz de responder ao pedido de auxílio do usuário ou dos seus familiares. Como tal, essa rede de serviços deve situar-se em um dado território e orientar-se pelos princípios da integralidade de ações e da intersetorialidade.

Também é necessário que os diversos segmentos da sociedade (gestores, trabalhadores de saúde, população em geral) possam conhecer os avanços em termos de legislação referente à doença mental, permitindo aos usuários um tratamento eficaz, em que sejam contemplados o exercício da cidadania, o acesso ao trabalho e a inclusão social. Para isso, ações voltadas a um melhor conhecimento da população internada, submissão dos hospitais psiquiátricos aos serviços territoriais - via central de vagas - e fiscalização e avaliação continuada dos hospitais e de seus projetos terapêuticos são dispositivos 
fundamentais para se viabilizar o modelo de atenção psicossocial.

Um último aspecto a ser observado relaciona-se à intensificação das ações junto à sociedade. Tais ações devem ter como objetivo produzir mudanças no imaginário social acerca da doença mental, da loucura, da anormalidade e da periculosidade do louco, bem como dos serviços de Saúde Mental enquanto um mero depositário de "doentes mentais".

Finalmente, é importante enfatizar os riscos advindos das indústrias farmacêuticas que enfrenta o processo de mudança do modelo de atenção em Saúde Mental ao se desenvolver, pois os interesses industriais se situam no polo dominante e são incompatíveis com um modelo assistencial substitutivo ao modelo psiquiátrico tradicional.

\section{REFERÊNCIAS}

Amarante, P. \& Torres, E. H. G. (2001). A constituição de novas práticas no campo da Atenção Psicossocial: análise de dois projetos pioneiros na Reforma Psiquiátrica no Brasil. Saúde em debate, (58) 25, p.26-34.

Arouca, S. (2002). Entrevista à Revista Radis - Comunicação em Saúde. Rio de Janeiro: Fundação Oswaldo Cruz, 03, p.18-21.

Brasil. Conselho Nacional de Saúde (2002a). Conferência Nacional de Saúde Mental, 3, Relatório da III Conferência. Brasília: Conselho Nacional de Saúde/Ministério da Saúde. Recuperado em 10 de setembro de 2003 em http://www.conselho.saude.gov.br/biblioteca/Relatorios/sau de_mental.pdf

Brasil. Ministério da Saúde (2004). Legislação em saúde mental: 1990-2004. Brasília: Ministério da Saúde.

Brasil. Ministério da Saúde (2000). Portaria $n^{o}$. 106, de 11 de fevereiro, que cria a modalidade de residências terapêuticas, destinadas a pacientes psiquiátricos com longa permanência hospitalar. Brasília: Ministério da Saúde, 2000a. Recuperado em 20 de fevereiro de 2002 em http://www.saude.gov.br/doc/Portarias/2000

Brasil. Ministério da Saúde (2001). Portaria $n^{\circ} 469$, de 06 de abril, que altera a sistemática de remuneração dos procedimentos de internação em hospital psiquiátrico e dá outras providências. Brasília: Ministério da Saúde. Recuperado em 23 de janeiro de 2008 em http://dtr2001.saude.gov.br/sas/portarias/port2001/GM/GM -469RP.htm

Brasil. Ministério da Saúde (2002). Manual do programa nacional de avaliação dos serviços hospitalares - PNASH, ed. 2002. Brasília: Ministério da Saúde/Secretaria de Assistência à Saúde/Departamento de Controle e Avaliação de Sistemas. Recuperado em 21 de outubro de 2002 em http://www.saude.gov.br/SAS/PNASH

Brasil. Ministério da Saúde (2005a). Portaria GM no 245, de 17 de fevereiro, que destina incentivo financeiro para implantação de Centros de Atenção Psicossocial e dá outras providências. Brasília: Ministério da Saúde, 2005. Recuperado em 23 de janeiro de 2008 em http://portal.saude.gov.br/portal/saude/cidadao/visualizar_t exto.cfm?idtxt $=23378$

Brasil. Ministério da Saúde/Ministério do Trabalho e Emprego (2005b). Portaria interministerial 353, de 7 de março, que institui o Grupo de Trabalho de Saúde Mental e Economia Solidária. Brasília: Ministério da Saúde/ Ministério do Trabalho e Emprego. Recuperado em 23 de janeiro de 2008 em http://portal.saude.gov.br/portal/saude/cidadao/visualizar_texto.cf m?idtxt=23123

Brasil. Ministério da Saúde (2005c). Portaria GM $n^{\circ}$ 1174, de 07 de julho, que destina incentivo financeiro emergencial para o Programa de Qualificação dos Centros de Atenção Psicossocial CAPS e dá outras providências. Brasília: Ministério da Saúde. Recuperado em 20 de novembro de 2005 em http://portal.saude.gov.br/portal/saude/cidadao/visualizar_texto.cf m?idtxt $=23377$

Brasil. Ministério da Saúde (2006a). Portaria $n^{\circ}$ 678, de 30 de março, que institui a Estratégia Nacional de Avaliação, Monitoramento, Supervisão e Apoio Técnico aos Centros de Atenção Psicossocial e outros serviços da rede pública de saúde mental do SUS. Brasília: Ministério da Saúde. Recuperado em 15 de setembro de 2006 em http://dtr2001.saude.gov.br/sas/PORTARIAS/Port2006/G M/GM-678.htm

Brasil. Ministério da Saúde (2006b). Portaria Interministerial $n^{o}$ 3.347 de 29 de dezembro de 2006, que institui o Núcleo Brasileiro de Direitos Humanos e Saúde Mental. Brasilia: Ministério da Saúde. Recuperado em 10 de abril de 2007 em: http://www.inverso.org.br/blob/175.doc

Brasil. Ministério da Saúde. Secretaria de Atenção à Saúde/DAPE (2007). Saúde Mental no SUS: acesso ao tratamento e mudança do modelo de atenção. Relatório de Gestão 2003-2006. Ministério da Saúde: Brasília.

Campos, G. W. S (1997). Reforma da Reforma: repensando a saúde. 2.ed. São Paulo: Hucitec.

Capistrano Filho, D. (2000). Os ritmos da Reforma: histórico, avaliação e diagnóstico. Em Conselho Federal de Psicologia (org.) Como anda a reforma psiquiátrica? Avaliação, perspectiva e prioridades. Brasília: CFP, p. 23-8.

Conselho Regional de Psicologia $-6^{\mathrm{a}}$ região/SP (1997). Trancar não é tratar - liberdade: o melhor remédio. 2.ed. São Paulo: CRP/6a .

Costa-Rosa, A., Luzio, C. A. \& Yasui, S. (2003). Atenção Psicossocial - rumo a um novo paradigma na Saúde Mental Coletiva. In P. Amarante (coord.), Archivos de Saúde Mental e Atenção Psicossocial. Rio de Janeiro: Nau, p. 13-44.

Levcovitz, E., Lima, L. D. \& Machado, C. V. (2001). Política de Saúde nos anos de 90: relações intergovernamentais e o papel das Normas Operacionais Básicas. Ciência e Saúde Coletiva, 6(2), p. 269-291.

Luzio, C. A. (2003). A Atenção em Saúde Mental em municípios de pequeno e médio portes: ressonâncias da Reforma Psiquiátrica. Tese de Doutorado Não Publicada, Programa de Pós-Graduação em Saúde Coletiva, Faculdade de Ciências Médicas, Universidade Estadual de Campinas, Campinas. 
Rotelli, F., Leonardi, O. \& Mauri, D. (2001). Desinstitucionalização uma outra via. Em F. Nicácio. (org) Desinstitucionalização. São Paulo: Hucitec.

Stotz, E. N. (1994). Movimentos sociais e saúde: notas para uma discussão. Cadernos de Saúde Pública, 10(2), p.264-268.

Yasui. S. (1999). A construção da reforma psiquiátrica e o seu contexto histórico. Dissertação de Mestrado Não-Publicada,
Curso de Pós-Graduação em Psicologia, Faculdade de Ciências e Letras de Assis, Universidade Estadual Paulista, Assis.

Recebido em 24/04/2008

Aceito em 12/11/2008

Endereço para correspondência:

Cristina Amélia Luzio. Faculdade de Ciências e Letras de Assis - UNESP, Departamento de Psicologia Evolutiva, Social e Escolar, Av. D. Antônio, 2100, Pq. Universitário, CEP 19806900, Assis-SP, Brasil.E-mail: caluzio@ assis.unesp.br. 